\title{
Survival and Health Care Use After Deep Brain Stimulation for Parkinson's Disease
}

\author{
James A.G. Crispo (D), Melody Lam, Britney Le, Salimah Z. Shariff, \\ Dominique R. Ansell, Melanie Squarzolo, Danielle Ouellette, Dylan P. Thibault, \\ Connie Marras, Allison W. Willis, Dallas Seitz.
}

\begin{abstract}
Objectives: To compare long-term survival of Parkinson's disease (PD) patients with deep brain stimulation (DBS) to matched controls, and examine whether DBS was associated with differences in injurious falls, long-term care, and home care. Methods: Using administrative health data (Ontario, Canada), we examined DBS outcomes within a cohort of individuals diagnosed with PD between 1997 and 2012. Patients receiving DBS were matched with non-DBS controls by age, sex, PD diagnosis date, time with PD, and a propensity score. Survival between groups was compared using the log-rank test and marginal Cox proportional hazards regression. Cumulative incidence function curves and marginal subdistribution hazard models were used to assess effects of DBS on falls, long-term care admission, and home care use, with death as a competing risk. Results: There were 260 DBS recipients matched with 551 controls. Patients undergoing DBS did not experience a significant survival advantage compared to controls (log-rank test $p=0.50 ;$ HR: 0.89, 95\% CI: $0.65-1.22$ ). Among patients $<65$ years of age, DBS recipients had a significantly reduced risk of death (HR: $0.49,95 \%$ CI: 0.28-0.84). Patients receiving DBS were more likely than controls to receive care for falls (HR: 1.56, 95\% CI: 1.19-2.05) and home care (HR: 1.59, 95\% CI: 1.32-1.90), while long-term care admission was similar between groups. Conclusions: Receiving DBS may increase survival for younger PD patients who undergo DBS. Future studies should examine whether survival benefits may be attributed to effects on PD or the absence of comorbidities that influence mortality.
\end{abstract}

RÉSUMÉ : Taux de survie et utilisation des soins de santé dans le cas de patients atteints de la maladie de Parkinson ayant bénéficié de la stimulation cérébrale profonde. Objectifs : Comparer le taux de survie à long terme de patients atteints de la maladie de Parkinson (MP) qui ont bénéficié de la stimulation cérébrale profonde (SCP) à celui de témoins appariés ; analyser dans quelle mesure la SCP a été associée à des variations en ce qui concerne le nombre de chutes avec blessures et la nécessité de soins de longue durée et de soins à domicile. Méthodes : C'est au moyen de données administratives ontariennes du domaine de la santé, plus précisément une cohorte d'individus chez qui l'on a diagnostiqué la MP entre 1997 et 2012 , que nous nous sommes attardés aux effets de la SCP. Des patients ayant bénéficiée de ce traitement ont ainsi été appariés en fonction de l'âge, du sexe, de la date du diagnostic de MP, de la durée de cette maladie et des scores de propension (propensity score) à des témoins qui n'en ont pas bénéficié. Les taux de survie de ces deux groupes ont été comparés au moyen du test de Mantel-Haenszel et du modèle de régression de Cox (MRC). Des courbes estimant la fonction d'incidence cumulée (cumulative incidence function curves) et des modèles de risque basés sur une sous-distribution marginale (marginal subdistribution hazard models) ont également été utilisés pour évaluer les effets de la SCP en ce qui regarde les chutes, les admissions à des centres de soins de longue durée et le recours à des soins à domicile, le fait de décéder étant ici un risque concurrent. Résultats : Au total, 260 patients ayant bénéficié de la SCP ont été appariés à 551 témoins. En gros, les premiers n'ont pas bénéficié d'un avantage significatif en termes de survie si on les compare aux témoins (test de Mantel-Haenszel p = 0,50; MRC : 0,89; IC $95 \%: 0,65-1,22$ ). Parmi les patients âgés de moins de 65 ans, ceux ayant bénéficié de la SCP ont donné à voir un risque de mortalité sensiblement réduit (MRC : 0,49; IC $95 \%: 0,28-0,84$ ). Les patients ayant bénéficié de la SCP ont également été plus susceptibles de recevoir des soins à la suite de chutes (MRC : 1,56; IC $95 \%: 1,19-2,05)$ ainsi que des soins à domicile (MRC : 1,59: IC $95 \%: 1,32-$ $1,90)$ tandis que les admissions dans des centres de soins de longue durée se sont révélées semblables d'un groupe à l'autre. Conclusions : En somme, il est possible que la SCP augmente le taux de survie de patients moins âgés qui sont atteints de la MP. Des études futures devraient examiner si ces avantages en termes de survie peuvent être attribués aux effets sur la MP ou bien à l'absence de comorbidités pouvant influencer la mortalité.

Keywords: Parkinson's disease, Deep brain stimulation, Ontario, ON-Marg

doi:10.1017/cjn.2020.187

Can J Neurol Sci. 2021; 48: 372-382

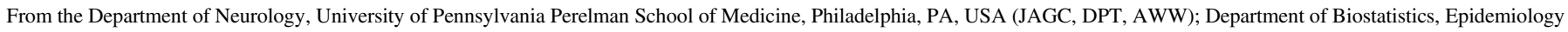

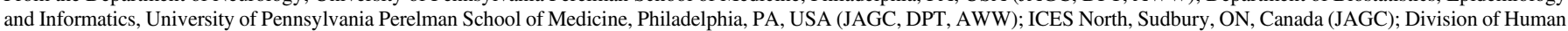

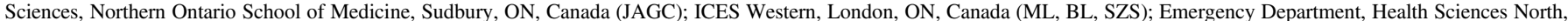

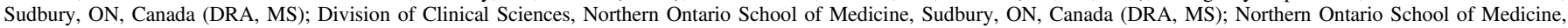

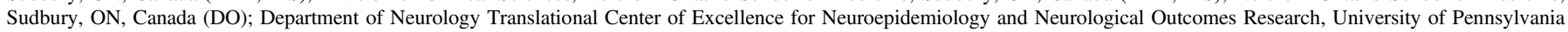

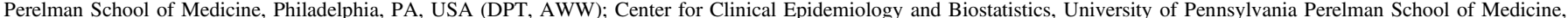

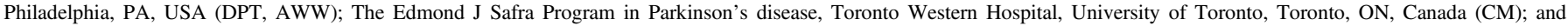
Department of Psychiatry, Queen's University, ICES-Queen's, Kingston, ON, Canada (DS)

Received May 29, 2020. Final Revisions Submitted August 12, 2020. Date of Acceptance August 18, 2020.

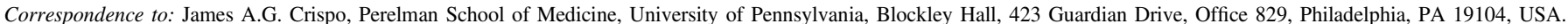
Email: jcris021@uottawa.ca 


\section{INTRODUCTION}

Estimates suggest that nearly 64,000 Ontarians aged 40 years or older will be living with Parkinson's disease (PD) by 2031, which is a $65 \%$ increase in the 2016 PD prevalence. ${ }^{1,2}$ Medication-based treatment strategies are most commonly used to manage PD symptoms; however, interventions such as physical therapy and deep brain stimulation (DBS) may also be effective. ${ }^{3-5}$ Although DBS is superior to PD medications for patients with difficult to control motor fluctuations or debilitating tremor ${ }^{6}$ and may contribute to functional and quality of life improvements, ${ }^{4,7}$ it remains underutilized. ${ }^{8-10}$ This is believed to reflect insufficient knowledge of DBS among primary care neurologists, overestimation of therapy risks, concerns regarding lack of effect, and patient preference. ${ }^{9}$

To date, four observational studies have examined long-term survival differences between DBS recipients for PD and controls who did not undergo DBS surgery. ${ }^{11-14}$ Two studies reported that DBS recipients experienced a significant survival advantage (31-71\% reduced likelihood of death) compared to medically managed patients, ${ }^{12,14}$ while two studies found no difference in survival between DBS and non-DBS groups. ${ }^{11,13}$ Inconsistent reports across previous studies leave important questions regarding the long-term benefits of DBS unanswered. This includes the effects of DBS, if any, on survival and indicators of disability and well-being, such as falls and admission to long-term care facilities. Knowledge of these effects is necessary to inform discussions about DBS surgery for PD, as well as health service planning for Canada's aging population.

The objective of our study was to compare the long-term survival of DBS recipients diagnosed with PD in Ontario, Canada to that of non-DBS controls with PD who were medically managed. Since use of publicly funded health care services may decrease with DBS-attributed improvements in motor function and activities of daily living, ${ }^{15}$ our secondary objectives were to examine whether receipt of DBS for PD was associated with differences in care for injurious falls, long-term care admission, and home care. In consideration of prior conflicting reports on DBS survival benefits in PD, ${ }^{11-14}$ we hypothesized that any increase in survival with DBS would be modest, and that it would coincide with lower utilization of health services.

\section{Methods}

\section{Study Design and Setting}

We performed a retrospective cohort study to examine outcomes following DBS surgery within a group of individuals 40 years of age or older who were diagnosed with incident PD between January 1, 1997 and December 31, 2012 in Ontario, Canada. Since Ontario has a publicly funded universal single-payer health care system, all recorded demographic and health care data for patients included in our cohort was available via linked health administrative datasets housed at ICES. ICES is an independent, non-profit research institute funded by an annual grant from the Ontario Ministry of Health and Long-Term Care. As a prescribed entity under Ontario's privacy legislation, ICES is authorized to collect and use health care data for the purposes of health system analysis, evaluation, and decision support. Secure access to these data is governed by policies and procedures that are approved by the Information and Privacy Commissioner of Ontario. The use of data for this project was authorized under section 45 of Ontario's
Personal Health Information Protection Act. Projects conducted under section 45 , by definition, do not require review by a Research Ethics Board. Important study details are summarized using the REporting of studies Conducted using Observational Routinelycollected Data (RECORD) statement (Supplementary Table 1).

\section{Data Sources}

Several datasets were used in our analyses, including the Canadian Institute for Health Information Discharge Abstract Database (DAD), the Canadian Institute for Health Information National Ambulatory Care Reporting System (NACRS), the Ontario Drug Benefit (ODB) Claims Database, the Ontario Health Insurance Plan (OHIP) Claims Database, the Ontario Mental Health Reporting System (OMHRS), the Registered Persons Database (RPDB), and the Home Care Database (HCD). In-depth information on datasets used in our study is provided in Supplementary Table 2.

The following coding systems were used to define diagnoses and procedures examined in our study: International Classification of Diseases, Ninth (ICD-9-CA) and Tenth (ICD-10-CA) Revision codes, Canadian Classification of Health Interventions (CCI) codes, Canadian Classification of Procedures (CCP) codes, and OHIP diagnostic and fee codes. Specific diagnosis and procedure definitions are described in Supplementary Table 3.

\section{Study Population}

Cohort entry was based on the diagnosis of PD between January 1, 1997 and December 31, 2012 according to a validated Ontario-based parkinsonism algorithm (sensitivity $=72.3 \%$; specificity $=99.9 \%$; positive predictive value $=79.5 \%$; negative predictive value $=99.9 \%)^{16}$ adapted for PD. Individuals with one or more PD diagnoses at least 30 days after their initial PD diagnosis but within 1 year were included in our cohort, with their initial PD diagnosis date considered their cohort entry date. At the time of cohort entry, we excluded individuals: (1) with a missing or invalid Ontario Health Card number; (2) with missing age or sex data; (3) with a documented death date on or before cohort entry; (4) who were not Ontario residents; and (5) who were not Ontario residents for 2 or more of the previous 5 years.

To minimize the possibility of including individuals with atypical PD or other movement disorders misclassified as PD in our cohort, we excluded those who were less than 40 years of age at cohort entry. Our cohort was limited to individuals with incident PD by excluding anyone with a diagnosis of PD during the 5 preceding years, and those diagnosed with secondary Parkinsonism, atypical Parkinsonism, or who received DBS surgery within the 5 preceding years or 1 year after cohort entry. We excluded individuals residing in long-term care at cohort entry. We also excluded individuals with a brain tumor diagnosis or neurosurgery consult (proxies for possible DBS surgery contraindication) during the 5 preceding years or 1 year after cohort entry. Finally, individuals who died during the year after cohort entry were excluded so that everyone was alive at the start of follow-up for DBS surgery.

\section{DBS and Controls}

The exposure of our study was DBS surgery, which was defined as the earliest date of DBS surgery during the follow-up period (1 year after cohort entry to December 31, 2017, the study 
end date), hereafter described as the index date. We did not subclassify surgery by surgical target (i.e., thalamus, globus pallidus, and/or subthalamic nucleus) since the specific target was unavailable in analyzed datasets. Pseudo index dates were randomly assigned to non-DBS controls during the follow-up period. Exclusions related to the index date were then applied to exposed and unexposed groups. Individuals who died prior to the index date, long-term care residents at the index date, and those who were not Ontario residents for 2 or more of the previous 5 years were excluded. We also excluded anyone diagnosed with secondary Parkinsonism, atypical parkinsonism, or a brain tumor during the 5 preceding years or 1 year after the index date.

\section{Sociodemographic and Health Care Characteristics}

The following sociodemographic characteristics were reported for DBS recipients and controls at the index date: age, sex, marginalization, and health care service region. Marginalization was assessed using the Ontario Marginalization Index (ON-Marg), which is a census- and geographically based index commonly used to explain inequalities in various measures of health and social wellbeing. ${ }^{17}$ Domains of ON-Marg (residential instability, material deprivation, dependency, and ethnic concentration) were reported using available ON-Marg data from the year (2001, 2006, 2011, or 2016) closest to each index date. Health care service regions were categorized according to Ontario's Local Health Integration Network (LHIN) boundaries [individually and grouped as northern (North East and North West) and southern (all others) regions; Supplementary Figure 1)]. The LHINs are provincial health authorities that oversee the planning, integration, and funding of health services across Ontario. $^{18}$

The Johns Hopkins ACG ${ }^{\circledR}$ System (version 10) Aggregated Diagnosis Groups (ADGs) ${ }^{19}$ was used to assess comorbidities diagnosed during the 2-year period prior to the index date. Diagnoses of dementia were measured throughout the 2-year period prior to the index date, while diagnoses of psychosis, stroke, suicide attempt, and injurious falls were measured during the 5 years preceding the index date.

We quantified patients' use of health services by determining the total number of health care encounters, as well as the number of emergency, psychiatrist, geriatrician, neurologist, and home care visits during the 2-year period prior to the index date. Access to primary care services was evaluated by determining whether patients had a primary care physician at the index date.

\section{Matching}

We used matching to control for potential confounders across exposed and unexposed groups. A propensity score for each individual was derived using a logistic regression model to estimate the probability of receiving DBS surgery and included the following factors: all ON-Marg domains (quintiles); ADG summary score; diagnoses of dementia, psychosis, stroke, suicide attempt, and fall (dichotomous variables); prior emergency department, psychiatrist, geriatrician, and neurologist visits (dichotomous variables); total number of health care visits; prior home care (dichotomous); and family physician roster status (dichotomous). Individuals who received DBS were then matched with up to fournon-DBS controls without replacement on patient age (+/- 1 year), sex, cohort entry date (+/- 365 days), time with PD at the index date (+/- 365 days; as a marker of PD severity), and the propensity score $(+/-0.2$ standard deviations of the logit of the propensity score). Unmatched and matched cohort assembly is described in Figure 1.

\section{Study Outcomes}

Duration of survival following the index date was our primary outcome. Accordingly, patients were followed from the index date to the date of their death (all-cause mortality) or December 31, 2017. Secondary outcomes included time to first injurious fall, long-term care placement, and home care visit. For injurious falls and longterm care placement, patients were followed from the index date to the earliest recorded event. To account for the use of home care services following DBS surgery, time to first home care visit was assessed starting 6 months after the index date to the study end date.

\section{Analyses}

Sociodemographic, care, and clinical characteristics of the unmatched and matched cohorts were reported using descriptive statistics. Variations in individual characteristics between DBS recipients and matched controls were assessed using a weighted standardized difference, with differences $>0.10$ for any variable considered to represent imbalance. Kaplan-Meier curves were plotted for exposed and unexposed groups, with differences in survival between the groups assessed using the log-rank test. A marginal Cox proportional hazards regression was used to estimate the effects of DBS surgery on the hazard of the occurrence of all-cause mortality. For secondary outcomes, cumulative incidence functions were plotted for exposed and unexposed groups; differences between groups were assessed using Gray's test. Marginal subdistribution hazard models were then used to estimate the effects of DBS surgery on the hazard of the occurrence of each secondary outcome. Death was considered a competing risk in all secondary outcome analyses. An alpha of 0.05 was set as the threshold for significance. Patient privacy was protected by suppressing cell sizes $\leq 5$. All data was analyzed using SAS version 9.4 (SAS Institute Inc., Cary, NC, US).

\section{Subgroup Analyses}

We stratified all analyses by age ( $40-65$ years and $65+$ years) and sex (female and male) to examine differences in our primary and secondary outcomes within these subgroups. Treatmentinteraction terms for age (DBS*age) and sex (DBS*sex) were included in the age and sex hazard models, respectively.

\section{Data Availability Statement}

The dataset from this study is held securely in coded form at ICES. While data sharing agreements prohibit ICES from making the dataset publicly available, access may be granted to those who meet pre-specified criteria for confidential access, available at www.ices.on.ca/DAS. The full dataset creation plan and underlying analytic code are available from the authors upon request, understanding that the computer programs may rely upon coding templates or macros that are unique to ICES and are therefore either inaccessible or may require modification. 

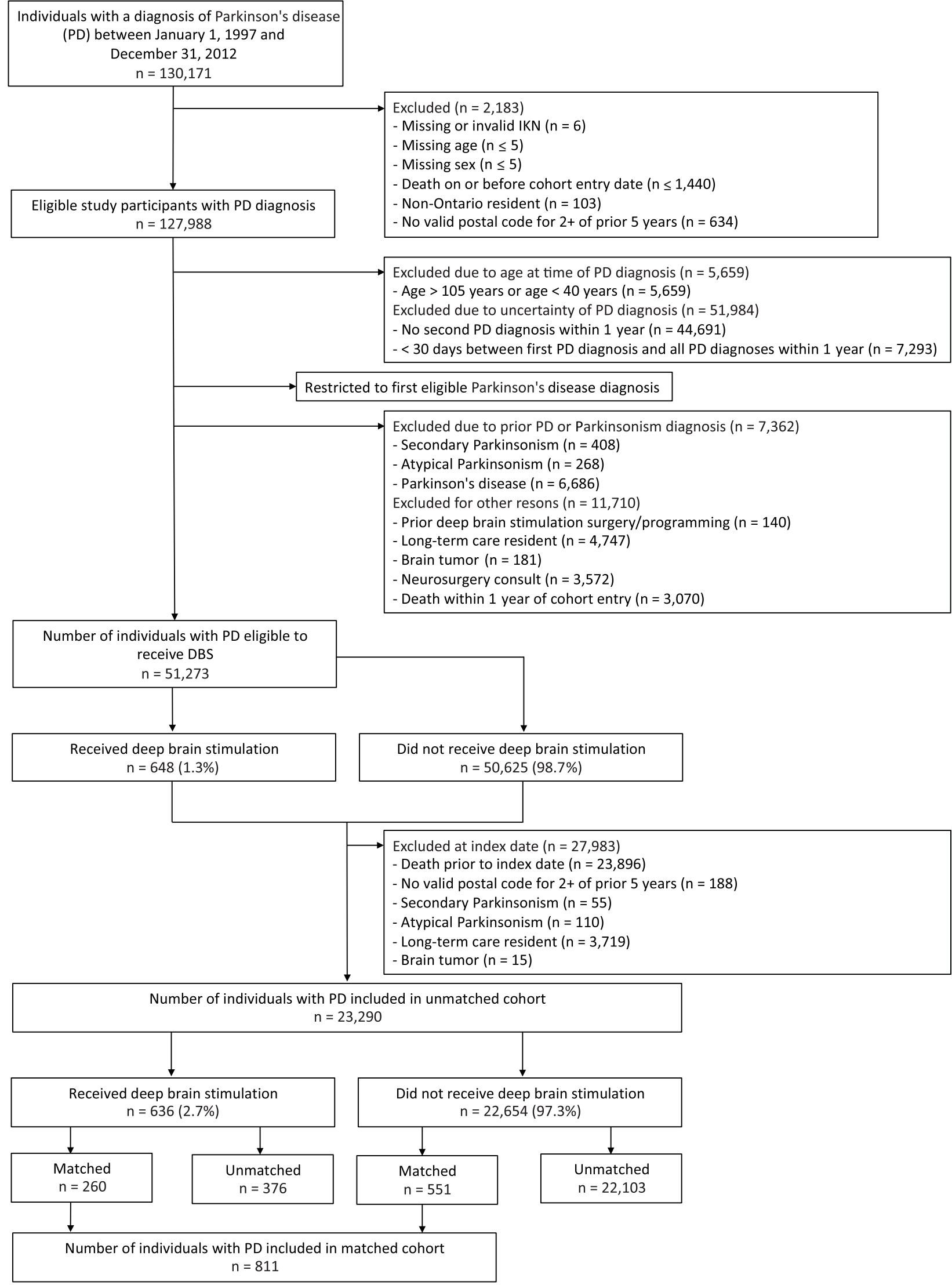

Figure 1: Cohort selection. 


\section{ReSUlts}

\section{Cohort Characteristics}

There were 51,273 adults aged 40 years or older diagnosed with incident PD between January 1, 1997 and December 31, 2012 who were eligible for inclusion in our unmatched cohort (Figure 1). Of these patients, $648(1.3 \%)$ received DBS surgery during the study follow-up period (1-year after cohort entry to December 31, 2017). After applying index date exclusion criteria, a total of 23,290 patients were included in our unmatched cohort (DBS $=636,2.7 \%$ ). The majority of patients diagnosed with PD were male $(56.1 \%)$, as were those who underwent DBS surgery (68.4\%). Mean age at time of DBS surgery was $61.7 \pm 7.3$ years, with patients having lived with PD for $9.1 \pm 3.6$ years prior to surgery. Most patients resided in southern Ontario $(94.5 \%)$ and were followed by a primary care physician $(78.9 \%)$. Injurious falls $(23.1 \%$ in prior five years) were common, as were the receipt of home care $(36.7 \%$ in prior two years) and emergency department visits (51.3\% in prior two years). Baseline characteristics are provided for the unmatched cohort in Supplementary Tables 4 and 5.

A total of 260 DBS recipients were matched with 551 nonDBS controls. Within the matched cohort, mean age at the time of DBS surgery was $64.4 \pm 6.9$ years and $74.6 \%$ of surgery recipients were men. Weighted standardized differences demonstrate minimal variation in measured baseline characteristics between DBS recipients and matched controls (Tables 1a and 1b).

\section{Survival}

Kaplan-Meier survival curves for DBS and non-DBS control groups are shown in Figure 2a. For these analyses, there were 3.1 [interquartile range (IQR): 1.0-5.7] and 3.1 (IQR: 1.3-5.6) median years of follow-up for the DBS and non-DBS groups, respectively. Compared to controls, there was no significant difference in survival probability for DBS recipients throughout the study follow-up period (log-rank test $\mathrm{p}=0.50$ ). Cox proportional hazards regression showed that there was no increased risk of death among DBS recipients relative to controls [hazard ratio (HR): 0.89, 95\% confidence interval (CI): 0.65-1.22] (Table 2).

\section{Secondary Outcomes}

The effects of DBS surgery on use of publicly funded health care services, including care for injurious falls, long-term care placement, and home care, are presented in Figure 2 and Table 2. For secondary outcome analyses, median follow-up time ranged from 0.8 (IQR: 0.0-2.7) to 2.7 (IQR: $0.8-5.3$ ) years and 1.7 (IQR: 0.6-3.6) to 2.9 (IQR: 1.2-5.2) years for the DBS and nonDBS groups, respectively. Differences in the plotted causespecific cumulative incidence functions between DBS recipients and non-DBS controls were observed for care related to injurious falls (Figure 2b; Gray's test $\mathrm{p}<0.01$ ) and use of home care services (Figure 2d; Gray's test $\mathrm{p}<0.01$ ), but not for long-term care placement (Figure 2c; Gray's test $\mathrm{p}=0.82$ ). Results from marginal subdistribution hazard modeling showed that DBS recipients were more likely to receive medical care for a fall (HR: 1.56, 95\% CI: 1.19-2.05) and more likely to receive care at home (HR: 1.59, 95\% CI: 1.32-1.90) than non-DBS controls, whereas the likelihood of being placed in long-term care was similar for both groups (HR: 1.11, 95\% CI: 0.75-1.65).
Descriptive statistics related to analyses of secondary outcomes, including the crude event rate and number of deaths within compared groups, are provided in Table 2.

\section{Subgroup Analyses}

Findings from our primary and secondary outcome analyses stratified by age and sex are presented in Supplementary Table 6. Significant DBS-age effects were observed for survival (interaction term $\mathrm{p}$ value $<0.01$ ) and long-term care placement (interaction $\mathrm{p}$ value $=0.02$ ) outcomes. No significant DBS-sex effects were observed.

Among patients $<65$ years of age, DBS recipients were less likely to die than non-DBS controls (HR: 0.49 , 95\% CI: $0.28-$ 0.84 ) during the study period. No significant differences in survival were observed when DBS surgery was performed at age 65 years or older (HR: 1.39, 95\% CI: 0.92-2.00). Moreover, older recipients of DBS were more likely to be admitted to longterm care than non-DBS controls of comparable ages (HR: 1.58, 95\% CI: 1.01-2.45). The likelihood of long-term care placement was similar among younger DBS and non-DBS groups (HR: 0.68, 95\% CI: 0.35-1.30).

\section{Discussion}

We used health administrative data from Ontario, Canada to compare the long-term survival of DBS recipients to that of nonDBS controls with PD who were medically managed. No significant difference in survival between recipients of DBS for PD and matched controls was observed. However, our subgroup analyses demonstrated significant heterogeneity of treatment effect by age, whereby patients treated with DBS at $<65$ years of age experienced a survival benefit compared to controls of similar ages. Notable secondary findings include: (1) DBS recipients were more likely than non-DBS controls to require medical care for injurious falls; (2) the overall likelihood of being admitted to a long-term care facility was similar between both treatment groups; (3) patients receiving DBS at age 65 years or older were more likely than non-DBS treated controls of comparable ages to be admitted to a long-term care facility; and (4) DBS recipients had a greater need for home care services than non-DBS controls.

It is well established that DBS is effective for the treatment of severe motor complications in PD, and that serious adverse events attributed to DBS surgery are relatively rare and reversible. $^{20-23}$ Currently, the effects of DBS compared to the medical management of PD on survival are unclear, and there are limited data on differences in long-term indicators of disability and wellbeing between these treatments. A number of studies have examined survival after DBS surgery for PD; ${ }^{1-14,24-29}$ however, few studies have compared the survival of DBS recipients to that of non-DBS controls with PD. ${ }^{11-14}$ Of reports comparing DBS recipients to patients that were medically managed, average survival effects are difficult to approximate due to design and analysis variability across studies. The first study on this topic was a single center study in the United Kingdom that examined survival between patients with severe PD who were eligible for and offered DBS between 2002 and 2012. Baseline characteristics between recipients of DBS surgery $(n=106)$ and patients that declined DBS surgery $(n=41)$ were similar. ${ }^{12}$ After adjustment for suspected confounders, investigators found that DBS recipients experienced significantly longer survival (HR: 0.29, 


\section{Table 1a: Sociodemographic characteristics of DBS cases and matched PD controls}

\begin{tabular}{|c|c|c|c|c|}
\hline & Total $(n=811)$ & No DBS $(\mathbf{n}=551)$ & DBS $(n=260)$ & WSD \\
\hline Age (years), mean (SD) ${ }^{\mathrm{a}}$ & $65.2 \pm 6.6$ & $65.6 \pm 6.4$ & $64.4 \pm 6.9$ & 0.01 \\
\hline Female, $\mathrm{n}(\%)^{\mathrm{a}}$ & $207(25.5 \%)$ & $141(25.6 \%)$ & $66(25.4 \%)$ & $<0.01$ \\
\hline \multicolumn{5}{|l|}{ ON-Marg: Residential instability, $\mathrm{n}(\%)^{\mathrm{b}}$} \\
\hline Quintile 1 (least marginalized) & $159(19.6 \%)$ & $114(20.7 \%)$ & $45(17.3 \%)$ & 0.11 \\
\hline Quintile 2 & $150(18.5 \%)$ & $101(18.3 \%)$ & $49(18.8 \%)$ & 0.04 \\
\hline Quintile 3 & $159(19.6 \%)$ & $110(20.0 \%)$ & $49(18.8 \%)$ & 0.04 \\
\hline Quintile 4 & $158(19.5 \%)$ & $109(19.8 \%)$ & $49(18.8 \%)$ & 0.02 \\
\hline Quintile 5 (most marginalized) & $185(22.8 \%)$ & $117(21.2 \%)$ & $68(26.2 \%)$ & 0.12 \\
\hline \multicolumn{5}{|l|}{ ON-Marg: Material deprivation, $\mathrm{n}(\%)^{\mathrm{b}}$} \\
\hline Quintile 1 (least marginalized) & $200(24.7 \%)$ & $133(24.1 \%)$ & $67(25.8 \%)$ & 0.04 \\
\hline Quintile 2 & $193(23.8 \%)$ & $136(24.7 \%)$ & $57(21.9 \%)$ & 0.03 \\
\hline Quintile 3 & $159(19.6 \%)$ & $106(19.2 \%)$ & $53(20.4 \%)$ & 0.01 \\
\hline Quintile 4 & $153(18.9 \%)$ & $102(18.5 \%)$ & $51(19.6 \%)$ & 0.02 \\
\hline Quintile 5 (most marginalized) & $106(13.1 \%)$ & $74(13.4 \%)$ & $32(12.3 \%)$ & $<0.01$ \\
\hline \multicolumn{5}{|l|}{ ON-Marg: Dependency, n $(\%)^{\mathrm{b}}$} \\
\hline Quintile 1 (least marginalized) & $148(18.2 \%)$ & $104(18.9 \%)$ & $44(16.9 \%)$ & 0.03 \\
\hline Quintile 2 & $143(17.6 \%)$ & $93(16.9 \%)$ & $50(19.2 \%)$ & 0.05 \\
\hline Quintile 3 & $143(17.6 \%)$ & $105(19.1 \%)$ & $38(14.6 \%)$ & 0.06 \\
\hline Quintile 4 & $170(21.0 \%)$ & $110(20.0 \%)$ & $60(23.1 \%)$ & 0.05 \\
\hline Quintile 5 (most marginalized) & $207(25.5 \%)$ & $139(25.2 \%)$ & $68(26.2 \%)$ & 0.01 \\
\hline \multicolumn{5}{|l|}{ ON-Marg: Ethnic concentration, $\mathrm{n}(\%)^{\mathrm{b}}$} \\
\hline Quintile 1 (least marginalized) & $161(19.9 \%)$ & $107(19.4 \%)$ & $54(20.8 \%)$ & 0.05 \\
\hline Quintile 2 & $174(21.5 \%)$ & $112(20.3 \%)$ & $62(23.8 \%)$ & 0.07 \\
\hline Quintile 3 & $151(18.6 \%)$ & $102(18.5 \%)$ & $49(18.8 \%)$ & 0.01 \\
\hline Quintile 4 & $165(20.3 \%)$ & $111(20.1 \%)$ & $54(20.8 \%)$ & $<0.01$ \\
\hline Quintile 5 (most marginalized) & $160(19.7 \%)$ & $119(21.6 \%)$ & $41(15.8 \%)$ & 0.12 \\
\hline \multicolumn{5}{|l|}{ Health Care Service Region (LHIN), n (\%) } \\
\hline Erie St. Clair (1) & $49(6.0 \%)$ & $29(5.3 \%)$ & $20(7.7 \%)$ & 0.15 \\
\hline South West (2) & $89(11.0 \%)$ & $45(8.2 \%)$ & $44(16.9 \%)$ & 0.29 \\
\hline Waterloo Wellington (3) & $48(5.9 \%)$ & $24(4.4 \%)$ & $24(9.2 \%)$ & 0.21 \\
\hline Hamilton Niagara Haldimand Brant (4) & $111(13.7 \%)$ & $76(13.8 \%)$ & $35(13.5 \%)$ & 0.03 \\
\hline Central West (5) & $38(4.7 \%)$ & $25(4.5 \%)$ & $13(5.0 \%)$ & 0.06 \\
\hline Mississauga Halton (6) & $56(6.9 \%)$ & $39(7.1 \%)$ & $17(6.5 \%)$ & 0.03 \\
\hline Toronto Central (7) & $68(8.4 \%)$ & $48(8.7 \%)$ & $20(7.7 \%)$ & 0.05 \\
\hline Central (8) & $100(12.3 \%)$ & $81(14.7 \%)$ & $19(7.3 \%)$ & 0.23 \\
\hline Central East (9) & $72(8.9 \%)$ & $56(10.2 \%)$ & $16(6.2 \%)$ & 0.17 \\
\hline South East (10) & $27(3.3 \%)$ & $17(3.1 \%)$ & $10(3.8 \%)$ & 0.05 \\
\hline Champlain (11) & $84(10.4 \%)$ & $66(12.0 \%)$ & $18(6.9 \%)$ & 0.17 \\
\hline North Simcoe Muskoka (12) & $32(3.9 \%)$ & $22(4.0 \%)$ & $10(3.8 \%)$ & 0.05 \\
\hline North East (13) & $25(3.1 \%)$ & $17(3.1 \%)$ & $8(3.1 \%)$ & 0.03 \\
\hline North West (14) & $12(1.5 \%)$ & $6(1.1 \%)$ & $6(2.3 \%)$ & 0.11 \\
\hline \multicolumn{5}{|l|}{ Grouped Regions, $\mathrm{n}(\%)^{\mathrm{c}}$} \\
\hline Southern Ontario (all southern LHINs) & $774(95.4 \%)$ & $528(95.8 \%)$ & $246(94.6 \%)$ & 0.04 \\
\hline Northern Ontario (North East \& North West) & $37(4.6 \%)$ & $23(4.2 \%)$ & $14(5.4 \%)$ & \\
\hline
\end{tabular}

DBS $=$ deep brain stimulation; LHIN $=$ Local Health Integration Network; ON-Marg $=$ Ontario Marginalization Index; PD $=$ Parkinson's disease; $\mathrm{SD}=$ standard deviation; WSD $=$ weighted standardized difference

${ }^{\mathrm{a}}$ Covariate used in matching of controls to cases.

${ }^{\mathrm{b}}$ Covariate used in propensity score model.

'Ontario's three DBS surgery sites are all located in Southern Ontario. 


\section{Table 1b: Clinical and provider characteristics of DBS cases and matched PD controls}

\begin{tabular}{|c|c|c|c|c|}
\hline & Total $(n=811)$ & No DBS $(\mathbf{n}=\mathbf{5 5 1})$ & DBS $(\mathbf{n}=\mathbf{2 6 0})$ & WSD \\
\hline \multicolumn{5}{|l|}{ PD diagnosis and duration } \\
\hline \multicolumn{5}{|c|}{ Year of PD diagnosis (cohort entry), $\mathrm{n}(\%)^{\mathrm{a}}$} \\
\hline 1997 & $131(16.2 \%)$ & $85(15.4 \%)$ & $46(17.7 \%)$ & $<0.01$ \\
\hline 1998 & $29(3.6 \%)$ & $20(3.6 \%)$ & $9(3.5 \%)$ & 0.05 \\
\hline 1999 & $18(2.2 \%)$ & $9(1.6 \%)$ & $9(3.5 \%)$ & 0.06 \\
\hline 2000 & $28(3.5 \%)$ & $18(3.3 \%)$ & $10(3.8 \%)$ & 0.03 \\
\hline 2001 & $29(3.6 \%)$ & $17(3.1 \%)$ & $12(4.6 \%)$ & 0.06 \\
\hline 2002 & $27(3.3 \%)$ & $18(3.3 \%)$ & $9(3.5 \%)$ & 0.08 \\
\hline 2003 & $38(4.7 \%)$ & $23(4.2 \%)$ & $15(5.8 \%)$ & 0.01 \\
\hline 2004 & $42(5.2 \%)$ & $30(5.4 \%)$ & $12(4.6 \%)$ & 0.05 \\
\hline 2005 & $55(6.8 \%)$ & $35(6.4 \%)$ & $20(7.7 \%)$ & 0.07 \\
\hline 2006 & $54(6.7 \%)$ & $35(6.4 \%)$ & $19(7.3 \%)$ & 0.02 \\
\hline 2007 & $59(7.3 \%)$ & $44(8.0 \%)$ & $15(5.8 \%)$ & 0.06 \\
\hline 2008 & $74(9.1 \%)$ & $52(9.4 \%)$ & $22(8.5 \%)$ & 0.01 \\
\hline 2009 & $71(8.8 \%)$ & $55(10.0 \%)$ & $16(6.2 \%)$ & 0.06 \\
\hline 2010 & $88(10.9 \%)$ & $61(11.1 \%)$ & $27(10.4 \%)$ & 0.09 \\
\hline 2011 & $47(5.8 \%)$ & $34(6.2 \%)$ & $13(5.0 \%)$ & 0.01 \\
\hline 2012 & $21(2.6 \%)$ & $15(2.7 \%)$ & $6(2.3 \%)$ & 0.03 \\
\hline Time with PD (years), mean (SD) ${ }^{\mathrm{a}}$ & $8.2 \pm 3.8$ & $8.0 \pm 3.8$ & $8.6 \pm 3.8$ & 0.03 \\
\hline \multicolumn{5}{|l|}{ Comorbidities in previous 2 years } \\
\hline \multicolumn{5}{|l|}{ ADGs, n (\%) } \\
\hline 0 & $\leq 5$ & $\leq 5$ & $0(0.0 \%)$ & 0.09 \\
\hline $1-2$ & $\leq 45$ & $\leq 40$ & $\leq 5$ & 0.23 \\
\hline $3-4$ & $153(18.9 \%)$ & $104(18.9 \%)$ & $49(18.8 \%)$ & 0.01 \\
\hline $5-6$ & $175(21.6 \%)$ & $131(23.8 \%)$ & $44(16.9 \%)$ & 0.15 \\
\hline $7+$ & $438(54.0 \%)$ & $276(50.1 \%)$ & $162(62.3 \%)$ & 0.23 \\
\hline ADG summary score, mean $(\mathrm{SD})^{\mathrm{b}}$ & $19.2 \pm 9.2$ & $19.0 \pm 9.1$ & $19.8 \pm 9.3$ & 0.16 \\
\hline Dementia, n $(\%)^{\mathrm{b}}$ & $11(1.4 \%)$ & $\leq 10$ & $\leq 5$ & 0.02 \\
\hline Psychosis, n $(\%)^{\mathrm{b}}$ & $62(7.6 \%)$ & $37(6.7 \%)$ & $25(9.6 \%)$ & 0.07 \\
\hline Stroke, $\mathrm{n}(\%)^{\mathrm{b}}$ & $40(4.9 \%)$ & $25(4.5 \%)$ & $15(5.8 \%)$ & 0.08 \\
\hline \multicolumn{5}{|l|}{ Injuries in previous 5 years, $\mathrm{n}(\%)$} \\
\hline Suicide attempt ${ }^{\mathrm{b}}$ & $\leq 5$ & $\leq 5$ & $\leq 5$ & 0.05 \\
\hline Fall $^{\mathrm{b}}$ & $142(17.5 \%)$ & $95(17.2 \%)$ & $47(18.1 \%)$ & 0.01 \\
\hline \multicolumn{5}{|c|}{ Health care utilization in previous 2 years, $\mathrm{n}(\%)$} \\
\hline Prior home care ${ }^{\mathrm{b}}$ & $216(26.6 \%)$ & $138(25.0 \%)$ & $78(30.0 \%)$ & 0.07 \\
\hline \multicolumn{5}{|l|}{ All health care visits ${ }^{b}$} \\
\hline Mean (SD) & $41.2 \pm 38.4$ & $38.5 \pm 42.4$ & $46.8 \pm 27.3$ & 0.25 \\
\hline \multicolumn{5}{|l|}{ Emergency department visits ${ }^{\mathrm{b}}$} \\
\hline Any visit & $379(46.7 \%)$ & $248(45.0 \%)$ & $131(50.4 \%)$ & 0.10 \\
\hline No visit & $432(53.3 \%)$ & $303(55.0 \%)$ & $129(49.6 \%)$ & \\
\hline \multicolumn{5}{|l|}{ Psychiatrist visits $^{\mathrm{b}}$} \\
\hline Any visit & $157(19.4 \%)$ & $90(16.3 \%)$ & $67(25.8 \%)$ & 0.01 \\
\hline No visit & $654(80.6 \%)$ & $461(83.7 \%)$ & $193(74.2 \%)$ & \\
\hline \multicolumn{5}{|l|}{ Geriatrician visits $^{\mathrm{b}}$} \\
\hline Any visit & $16(2.0 \%)$ & $10(1.8 \%)$ & $6(2.3 \%)$ & 0.04 \\
\hline No visit & $795(98.0 \%)$ & $541(98.2 \%)$ & $254(97.7 \%)$ & \\
\hline
\end{tabular}


Table 1b. (Continued)

\begin{tabular}{l|c|c|c|c}
\hline & Total $(\mathbf{n}=\mathbf{8 1 1})$ & No DBS $(\mathbf{n}=\mathbf{5 5 1})$ & DBS $(\mathbf{n}=\mathbf{2 6 0})$ & \\
\hline Neurologist visits $^{\mathrm{b}}$ & & & & \\
\hline 4+ visits & $450(55.5 \%)$ & $279(50.6 \%)$ & $171(65.8 \%)$ & \\
\hline $1-3$ visits & $339(41.8 \%)$ & $256(46.5 \%)$ & $83(31.9 \%)$ & 0.33 \\
\hline No visit & $22(2.7 \%)$ & $16(2.9 \%)$ & $6(2.3 \%)$ & 0.29 \\
\hline Primary care physician status & & & & 0.10 \\
\hline Rostered to a primary care physician; $\mathrm{n}(\%)^{\mathrm{b}}$ & $667(82.2 \%)$ & $449(81.5 \%)$ & $218(83.8 \%)$ & \\
\hline
\end{tabular}

$\mathrm{ADG}=$ Aggregated Diagnosis Group; DBS = deep brain stimulation; LHIN = Local Health Integration Network; PD = Parkinson's disease; SD = standard deviation; WSD = weighted standardized difference.

${ }^{\mathrm{a}}$ Covariate used in matching of controls to cases.

${ }^{\mathrm{b}}$ Covariate used in propensity score model.

(a) All-cause mortality ${ }^{a}$

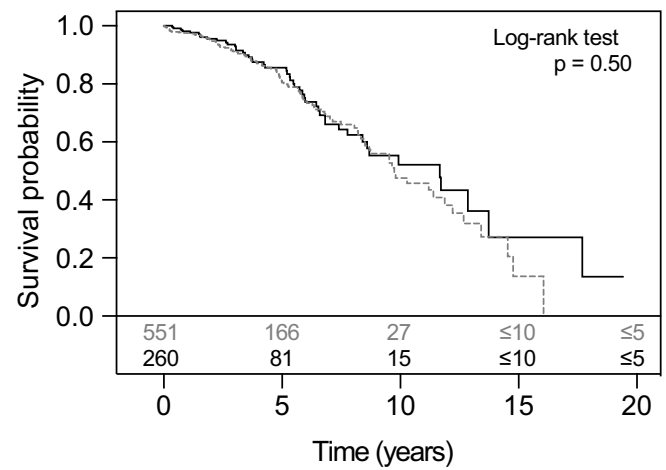

(c) Long-term care ${ }^{b}$

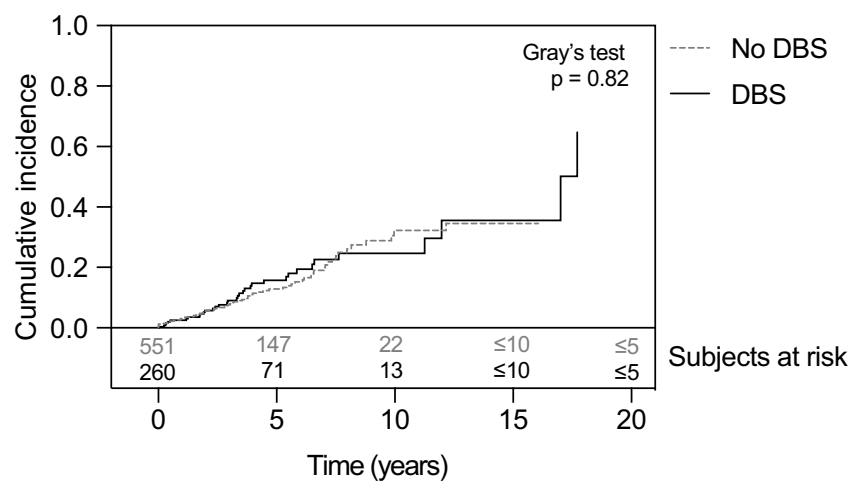

(b) Injurious falls ${ }^{b}$

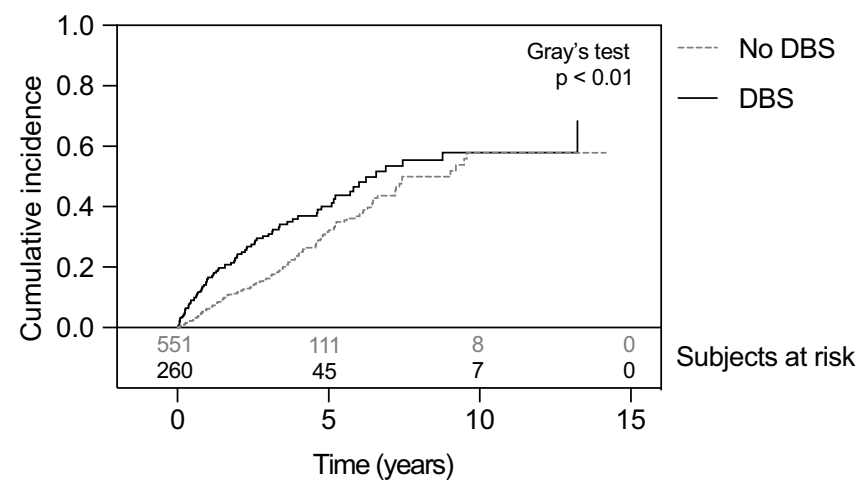

(d) Home care ${ }^{\text {b }}$

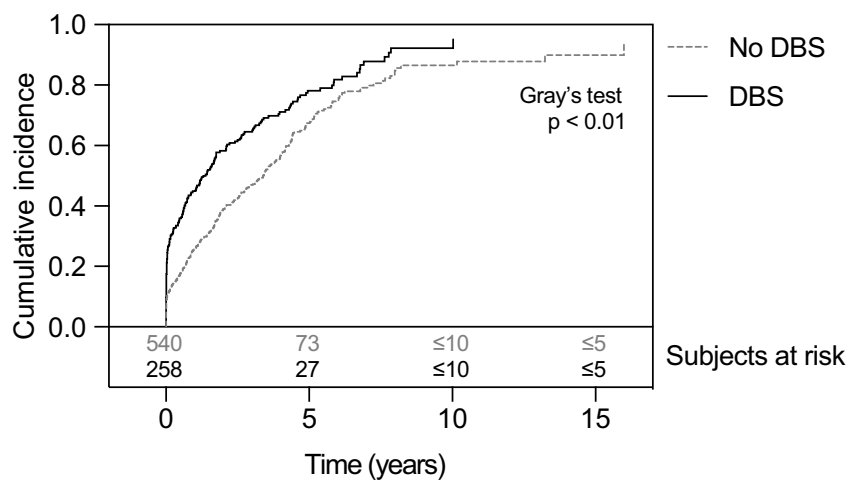

Figure 2: Kaplan-Meier survival curves and cumulative incidence functions.

Abbreviations: DBS, deep brain stimulation.

${ }^{a}$ Primary outcome.

${ }^{b}$ Secondary outcome.

95\% CI: 0.13-0.64). The small sample size of this study and possibility that patients who refused DBS were systematically different than DBS recipients leads to uncertainty in interpreting the reported findings. A separate US-based study of older veterans also reported increased survival among PD patients treated with DBS $(\mathrm{n}=611)$ compared to medically managed patients $(\mathrm{n}=611)$ (HR: 0.69, 95\% CI: 0.56-0.85). ${ }^{14}$ While authors report a modest survival advantage among DBS recipients (7.6 months), the possibility remains that survival differences were attributed to unmeasured inequalities in baseline comorbidities or PD duration. Additionally, the reported survival benefit with DBS may not be generalizable to non-veteran populations with PD.

Two studies provide evidence in support of the notion that DBS surgery does not modify PD or offer neuroprotective effects. ${ }^{11,13}$ The first was a study in Norway that compared patients who received DBS surgery $(n=81)$ at Oslo University Hospital between 2001 and 2007 to patients identified during a 1993 regional PD prevalence study who were medically managed 
Table 2: Hazard ratio for primary and secondary outcomes

\begin{tabular}{|c|c|c|c|c|c|c|c|c|c|c|}
\hline Outcome & Treatment & $\begin{array}{c}\text { Number of } \\
\text { patients }\end{array}$ & $\begin{array}{l}\text { Number } \\
\text { of events }\end{array}$ & $\begin{array}{c}\text { Crude } \\
\text { event } \\
\text { rate }(\%)\end{array}$ & $\begin{array}{c}\text { Total } \\
\text { person- } \\
\text { years } \\
\text { follow-up }\end{array}$ & $\begin{array}{c}\text { Event rate } \\
\text { per } 100 \\
\text { person- } \\
\text { years }\end{array}$ & $\begin{array}{l}\text { Median years } \\
\text { follow-up } \\
\text { (IQR) }\end{array}$ & $\begin{array}{l}\text { Number } \\
\text { of deaths }\end{array}$ & HR $(95 \%$ CI $)$ & $P$ value \\
\hline \multirow[t]{2}{*}{ All-cause mortality ${ }^{\mathrm{a}, \mathrm{c}}$} & No DBS & 551 & 106 & 19.2 & 2087.1 & 5.1 & $3.1(1.3-5.6)$ & - & Reference & - \\
\hline & DBS & 260 & 49 & 18.8 & 1001.9 & 4.9 & $3.1(1.0-5.7)$ & - & $0.89(0.65-1.22)$ & 0.47 \\
\hline \multirow[t]{2}{*}{ Injurious falls ${ }^{\mathrm{b}, \mathrm{c}}$} & No DBS & 551 & 134 & 24.3 & 1648.5 & 8.1 & $2.4(1.0-4.4)$ & 57 & Reference & - \\
\hline & DBS & 260 & 84 & 32.3 & 671.3 & 12.5 & $1.9(0.6-3.7)$ & 23 & $1.56(1.19-2.05)$ & $<0.01$ \\
\hline \multirow[t]{2}{*}{ Long-term care ${ }^{\mathrm{b}, \mathrm{c}}$} & No DBS & 551 & 67 & 12.2 & 1920.5 & 3.5 & $2.9(1.2-5.2)$ & 70 & Reference & - \\
\hline & DBS & 260 & 35 & 13.5 & 908.9 & 3.9 & $2.7(0.8-5.3)$ & 28 & $1.11(0.75-1.65)$ & 0.59 \\
\hline \multirow[t]{2}{*}{ Home care ${ }^{\mathrm{b}, \mathrm{d}}$} & No DBS & 540 & 311 & 57.6 & 1288.3 & 24.1 & $1.7(0.6-3.6)$ & 13 & Reference & - \\
\hline & DBS & 258 & 187 & 72.5 & 448.5 & 41.7 & $0.8(0.0-2.7)$ & 6 & $1.59(1.32-1.90)$ & $<0.01$ \\
\hline
\end{tabular}

$\mathrm{CI}=$ confidence interval; $\mathrm{IQR}=$ interquartile range; $\mathrm{HR}=$ hazard ratio.

${ }^{\text {a}}$ Primary outcome.

${ }^{\mathrm{b}}$ Secondary outcome.

c811 patients (260 DBS recipients, 551 controls) included in analysis.

${ }^{\mathrm{d}} 798$ patients (258 DBS recipients, 540 controls) included in analysis.

$(\mathrm{n}=90) .{ }^{11}$ Authors reported a non-significant trend towards a greater risk of mortality for DBS recipients in their age-matched analyses (HR: 1.76, 95\% CI: 0.91-3.40). However, inclusion criteria for this study likely introduced bias in favor of the control group, since medically managed patients were required to live for a minimum of 4 years prior to being eligible for entry into the investigators' analytical cohort. ${ }^{30}$ The most recent study in this area is an Italian mulitcenter study of long-term outcomes among DBS recipients $(n=91)$ who were age- and gender-matched to non-DBS controls $(n=91)$, in which a minimum of 1-year follow-up for all patients was required. ${ }^{13}$ Mortality rates were similar between groups, which may reflect the minimal total follow-up time for each group (367.5 and 230.7 person-years for the DBS group and non-DBS group, respectively).

Our study is the first community-based study to examine differences in survival between PD patients treated with DBS and patients who were medically managed. It therefore meaningfully adds to the aforementioned conflicting reports on this topic and increases the weight of evidence that there are no significant longterm survival benefits associated with DBS for PD (HR: 0.89, 95\% CI: 0.65-1.22). Despite this finding, potential gains in motor function, activities of daily living, and health-related quality of life afforded by DBS make it an important therapeutic consideration in the treatment of PD. ${ }^{6}$ Our study is the first to examine survival differences related to DBS at different ages. Our finding that younger DBS recipients experience significantly longer survival than age-matched controls (HR: $0.49,95 \%$ CI: $0.28-0.84$ ) constructively adds to the ongoing discourse about risks and benefits of using DBS for the treatment of earlier and less advanced PD. ${ }^{21,31,32}$ Reasons for this finding remain to be explored; however, it is possible that surgical intervention at an earlier age positively affects comorbidities that may reduce survival. If replicated, knowledge of survival benefits related to DBS surgery at an earlier age may narrow widespread clinician and patient perspectives regarding the earlier use of DBS for PD. ${ }^{33,34}$
Randomized controlled trials (RCTs) and observational studies have examined differences in the risk of falling between PD patients treated with DBS or best medical therapy. One RCT found that DBS recipients $(n=121)$ were significantly more likely to experience injurious falls within 6 months of randomization than patients in the best medical therapy group $(n=134) .{ }^{35}$ Conversely, a separate $\mathrm{RCT}$ reported that the rate of serious falls requiring medical attention within the year following study entry was similar between DBS $(n=183)$ and medically managed groups $(n=183) .{ }^{36}$ Most recently, a small pilot observational study found that patients treated with DBS $(n=91)$ had a non-significantly reduced risk of injurious falls compared to non-DBS controls $(\mathrm{n}=91)$ (adjusted relative risk: $0.61,95 \%$ CI: $0.25-1.46) .{ }^{13}$ Our study of the long-term risk of falling between DBS and non-DBS groups includes the largest number of individuals with $\mathrm{PD}$ and greatest total number of person-years follow-up. We show that DBS recipients were more likely to require medical intervention for a fall than medically managed patients. It is unclear whether the observed number of falls in the DBS group is associated with their improved motor function and therefore greater level of activity, or effects of DBS on postural stability. Nevertheless, the DBS group event rate for injurious falls $(32.3 \%)$ suggests that clinicians should routinely discuss fall risk-precautions with these patients.

Information regarding use of long-term care between DBS recipients and medically managed patients is limited. A single cohort study from the United Kingdom found that recipients of DBS were less likely to be admitted to a long-term care facility (HR: 0.10, 95\% CI: 0.03-0.29); citing improvements in motor function and health-related quality of life as possible explanations for their observation. ${ }^{12}$ In Ontario, we show that there is no difference in admission to long-term care between DBS and non-DBS groups (HR: $1.11,95 \%$ CI: 0.75-1.65). Differences in findings across studies may in part be explained by regional variations in the care for PD, including the use of home care and the availability of outpatient support groups and services. To our knowledge, no prior 
studies have examined the effect of DBS on the use of home care services. Our finding that DBS recipients were more likely to utilize home care services may be attributed to outpatient care for fallrelated trauma. This however remains to be explored in future investigations.

Our study has a number of strengths. To our knowledge, it is the single largest study to date to examine survival following DBS surgery within a community-based cohort of individuals living with PD and universal health insurance. Patients included in our study were selected using an adapted version of a validated algorithm to identify individuals with Parkinsonism, ${ }^{16}$ and drawn from the same general population in Ontario, Canada for which the original algorithm was developed. Parkinsonism-causing conditions other than PD were excluded from our adapted PD algorithm. This was presumed to minimally impact algorithm performance since more than $80 \%$ of referent cases analyzed as part of the original algorithm's development had PD. ${ }^{16}$ Despite expert agreement that PD duration may confound survival analyses related to DBS surgery, our study is the first multicenter to include this important variable in its design or analysis. Furthermore, propensity score and hard matching ensured balance in key covariates across exposed and unexposed groups. Our study was not limited to a single centre or a particular subpopulation of patients with PD, and eligible non-DBS controls were selected from the same source population as DBS recipients. Therefore, our findings may be generalizable to other populations with PD, particularly those living in areas with publicly funded health services.

There are important limitations to consider when interpreting our findings. Our method of including DBS recipients and non-DBS controls in our unmatched cohort may be inherently subject to selection bias. Specifically, DBS recipients may have a higher probability of truly having PD than non-DBS controls. This could arise from non-DBS controls being more likely misclassified than DBS recipients as having PD within the analyzed health administrative datasets. Also, we were unable to determine what proportion of non-DBS controls declined offers of DBS surgery or had contraindications for DBS surgery (such as dominant levodopa-resistant motor symptoms that could not be assessed by our study). ${ }^{37}$ Conversely, misclassification of DBS surgery is unlikely, and misclassification of other measured variables is thought to minimally bias reported estimates. Populations with publicly funded insurance other than the Ontario Health Insurance Plan, such as First Nations People living on reserves and serving members of the Canadian Forces, were not included in our analyses. Our findings may therefore be less generalizable to the PD care of populations not represented within our analyses. While we utilized stringent design and analytical methods to reduce the potential for study bias, we could not control for select factors that may confound examined relationships, including PD severity and medication use. Studies with more detailed data on these elements, including detailed information on the use of antiparkinsonian drugs, antipsychotics, and medications affecting the central nervous system, are therefore necessary to assess the reproducibility of our findings. Notwithstanding study limitations, our findings add to the paucity of data on differences in long-term outcomes between DBS recipients and medically managed PD patients.

\section{Conclusions \& Future Directions}

In summary, our analyses demonstrate that DBS for PD is not associated with increased overall survival compared to best medical therapy across the age spectrum, but that receipt of DBS at an earlier age may contribute to longer life expectancy. Known improvements in motor function and health-related quality of life that may be offered by DBS likely outweigh any real differences in life expectancy between DBS and medically managed patients.

Candidates for DBS will consider perceived treatment benefits and risks, and personal preferences when deciding whether to opt for DBS surgery. It is therefore important for clinicians to refer patients to specialty care soon after the diagnosis of PD, and for specialists to thoroughly discuss all therapeutic treatment options with patients. Replication of our analyses within other populations is necessary. Nevertheless, our findings also show that DBS for PD may increase the need for fall-related care and use of home care services balanced against a potential increase in survival. Future studies should aim to examine whether the requirement for these health services may be prevented.

\section{ACKNOWLEDGEMENTS}

Parts of this material are based on data and/or information compiled and provided by CIHI. However, the analyses, conclusions, opinions and statements expressed in the material are those of the author(s), and not necessarily those of CIHI. We thank IMS Brogan Inc. for use of their Drug Information Database.

\section{Statement of Authorship}

All authors provided study design input. BL performed all data analyses and provided guidance on statistical analyses. ML, JAGC, AWW, CM, and DS led the interpretation of results. JAGC drafted the final manuscript. All authors contributed to manuscript revisions and approve the final manuscript.

\section{Disclosures}

JAGC, ML, BL, SZS, DRA, MS, DO, DPT, CM, and AWW declare no potential conflicts of interest with respect to the research, authorship, and/or publication of this article. DS served as a site investigator in a clinical trial by Hoffmann La Roche during the 36 months prior to publication; however, these activities were outside of the submitted work.

\section{Study Funding}

This study was supported by ICES, which is funded by an annual grant from the Ontario Ministry of Health and Long-Term Care (MOHLTC). The study was completed at the ICES Western site, where core funding is provided by the Academic Medical Organization of Southwestern Ontario (AMOSO), the Schulich School of Medicine and Dentistry (SSMD), Western University, and the Lawson Health Research Institute (LHRI). The opinions, results and conclusions reported in this paper are those of the authors and are independent from the funding sources. No endorsement by ICES, AMOSO, SSMD, LHRI, or the Ontario MOHLTC is intended or should be inferred. This study was also supported by the Northern Ontario Academic Medicine Association (NOAMA) Clinical Innovation Opportunities Fund Award, Project No: C-17-20. 


\section{SupPlementary Material}

To view supplementary material for this article, please visit https://doi.org/10.1017/cjn.2020.187.

\section{REFERENCES}

1. Parkinson Canada. A plan for Parkinson's in Ontario. Available at: http://www.parkinson.ca/wp-content/uploads/OntAdvocacy_ 8.5x11_F.pdf; accessed April 15, 2020.

2. Lachance C, Spry C, MacDougall D. CADTH Rapid Response Reports. Deep Brain Stimulation for Parkinson's Disease: A Review of Clinical Effectiveness, Cost-Effectiveness, and Guidelines. Ottawa (ON): Canadian Agency for Drugs and Technologies in Health Copyright (c) 2018 Canadian Agency for Drugs and Technologies in Health; 2018.

3. Anderson D, Beecher G, Ba F. Deep Brain Stimulation in Parkinson's Disease: New and Emerging Targets for Refractory Motor and Nonmotor Symptoms. Parkinsons Dis. 2017;2017:5124328.

4. Giugni JC, Okun MS. Treatment of advanced Parkinson's disease. Current Opin Neurol. 2014;27(4):450-60.

5. Okun MS. Deep-brain stimulation for Parkinson's disease. N Engl J Med. 2012;367(16):1529-38.

6. Ponce FA, Lozano AM. Deep brain stimulation state of the art and novel stimulation targets. Prog Brain Res. 2010;184:311-24

7. Martinez-Ramirez D, Hu W, Bona AR, Okun MS, Wagle Shukla A. Update on deep brain stimulation in Parkinson's disease. Transl Neurodegener. 2015;4:12.

8. Chan AK, McGovern RA, Brown LT, et al. Disparities in access to deep brain stimulation surgery for Parkinson disease: interaction between African American race and Medicaid use. JAMA Neurol. 2014;71(3):291-9.

9. Lange M, Mauerer J, Schlaier J, et al. Underutilization of deep brain stimulation for Parkinson's disease? A survey on possible clinical reasons. Acta Neurochir (Wien). 2017;159(5):771-8.

10. Willis AW, Schootman M, Kung N, Wang XY, Perlmutter JS, Racette BA. Disparities in deep brain stimulation surgery among insured elders with Parkinson disease. Neurology. 2014;82(2): 163-71.

11. Lilleeng B, Bronnick K, Toft M, Dietrichs E, Larsen JP. Progression and survival in Parkinson's disease with subthalamic nucleus stimulation. Acta Neurol Scand. 2014;130(5):292-8.

12. Ngoga D, Mitchell R, Kausar J, Hodson J, Harries A, Pall H. Deep brain stimulation improves survival in severe Parkinson's disease. J Neurol Neurosurg Psychiatry. 2014;85(1):17-22.

13. Scelzo E, Beghi E, Rosa M, et al. Deep brain stimulation in Parkinson's disease: a multicentric, long-term, observational pilot study. J Neurol Sci. 2019;405:116411.

14. Weaver FM, Stroupe KT, Smith B, et al. Survival in patients with Parkinson's disease after deep brain stimulation or medical management. Mov Disord. 2017;32(12):1756-63.

15. Krack P, Batir A, Van Blercom N, et al. Five-year follow-up of bilateral stimulation of the subthalamic nucleus in advanced Parkinson's disease. N Engl J Med. 2003;349(20):1925-34.

16. ButtDA, Tu K, Young J, et al. A validation study of administrative data algorithms to identify patients with Parkinsonism with prevalence and incidence trends. Neuroepidemiology. 2014;43(1):28-37.

17. Matheson, FI; Ontario Agency for Health Protection and Promotion (Public Health Ontario). 2016 Ontario marginalization index: user guide. Toronto, ON: Providence St. Joseph's and St. Michael's Healthcare; 2018. Joint publication with Public Health Ontario.

18. MacLeod H. Local health integration networks: build on their purpose. Healthc Manag. 2015;28(6):242-6.

19. Weiner JP, Abrams C. The Johns Hopkins ACG system: technical reference guide version 10.0. Available at: https://www. healthpartners.com/ucm/groups/public/@hp/@ public/documents/ documents/cntrb_035024.pdf; accessed April 15, 2020.
20. Buhmann C, Huckhagel T, Engel K, et al. Adverse events in deep brain stimulation: a retrospective long-term analysis of neurological, psychiatric and other occurrences. PloS one. 2017;12(7): e0178984

21. deSouza RM, Moro E, Lang AE, Schapira AH. Timing of deep brain stimulation in Parkinson disease: a need for reappraisal? Ann Neurol. 2013;73(5):565-75.

22. Seijo F, Alvarez de Eulate Beramendi S, Santamarta Liebana E, et al. Surgical adverse events of deep brain stimulation in the subthalamic nucleus of patients with Parkinson's disease. The learning curve and the pitfalls. Acta Neurochir (Wien). 2014; 156(8):1505-12; discussion 12.

23. Vergani F, Landi A, Pirillo D, Cilia R, Antonini A, Sganzerla EP. Surgical, medical, and hardware adverse events in a series of 141 patients undergoing subthalamic deep brain stimulation for Parkinson disease. World Neurosurg. 2010;73(4):338-44.

24. Bang Henriksen M, Johnsen EL, Sunde N, Vase A, Gjelstrup MC, Ostergaard K. Surviving 10 years with deep brain stimulation for Parkinson's disease-a follow-up of 79 patients. Eur J Neurol. 2016;23(1):53-61.

25. Lau B, Meier N, Serra G, et al. Axial symptoms predict mortality in patients with Parkinson disease and subthalamic stimulation. Neurology. 2019;92(22):e2559-e70.

26. Levi V, Carrabba G, Rampini P, Locatelli M. "Short term surgical complications after subthalamic deep brain stimulation for Parkinson's disease: does old age matter?". BMC Geriatr. 2015; 15:116.

27. Ryu HS, Kim MS, You S, et al. Mortality of advanced Parkinson's disease patients treated with deep brain stimulation surgery. J Neurol Sci. 2016;369:230-5.

28. Toft M, Lilleeng B, Ramm-Pettersen J, et al. Long-term efficacy and mortality in Parkinson's disease patients treated with subthalamic stimulation. Mov Disord. 2011;26(10):1931-4.

29. Wider C, Pollo C, Bloch J, Burkhard PR, Vingerhoets FJ. Long-term outcome of 50 consecutive Parkinson's disease patients treated with subthalamic deep brain stimulation. Parkinsonism Relat Disord. 2008;14(2):114-9.

30. Contarino MF, Marinus J, van Hilten JJ. Does deep brain stimulation of the subthalamic nucleus prolong survival in Parkinson's Disease? Mov Disord. 2018;33(6):947-9.

31. Jiang L, Poon WS, Moro E, et al. Early versus Late Application of Subthalamic deep brain Stimulation to Parkinson's disease patients with motor complications (ELASS): protocol of a multicentre, prospective and observational study. BMJ Open. 2017; 7(11):e018610.

32. Merola A, Romagnolo A, Bernardini A, et al. Earlier versus later subthalamic deep brain stimulation in Parkinson's disease. Parkinsonism Relat Disord. 2015;21(8):972-5.

33. Cabrera LY, Kelly-Blake K, Sidiropoulos C. Perspectives on Deep Brain Stimulation and Its Earlier Use for Parkinson's Disease: A Qualitative Study of US Patients. Brain Sci. 2020;10(1).

34. Cabrera LY, Sarva H, Sidiropoulos C. Perspectives on the Earlier Use of Deep Brain Stimulation for Parkinson Disease from a Qualitative Study of U.S. Clinicians. World Neurosurg. 2019; 128:e16-e20.

35. Weaver FM, Follett K, Stern M, et al. Bilateral deep brain stimulation vs best medical therapy for patients with advanced Parkinson disease: a randomized controlled trial. JAMA. 2009;301(1): 63-73.

36. Williams A, Gill S, Varma T, et al. Deep brain stimulation plus best medical therapy versus best medical therapy alone for advanced Parkinson's disease (PD SURG trial): a randomised, open-label trial. Lancet Neurol. 2010;9(6):581-91.

37. Kocabicak E, Temel Y, Hollig A, Falkenburger B, Tan S. Current perspectives on deep brain stimulation for severe neurological and psychiatric disorders. Neuropsych Dis Treat. 2015;11: 1051-66. 